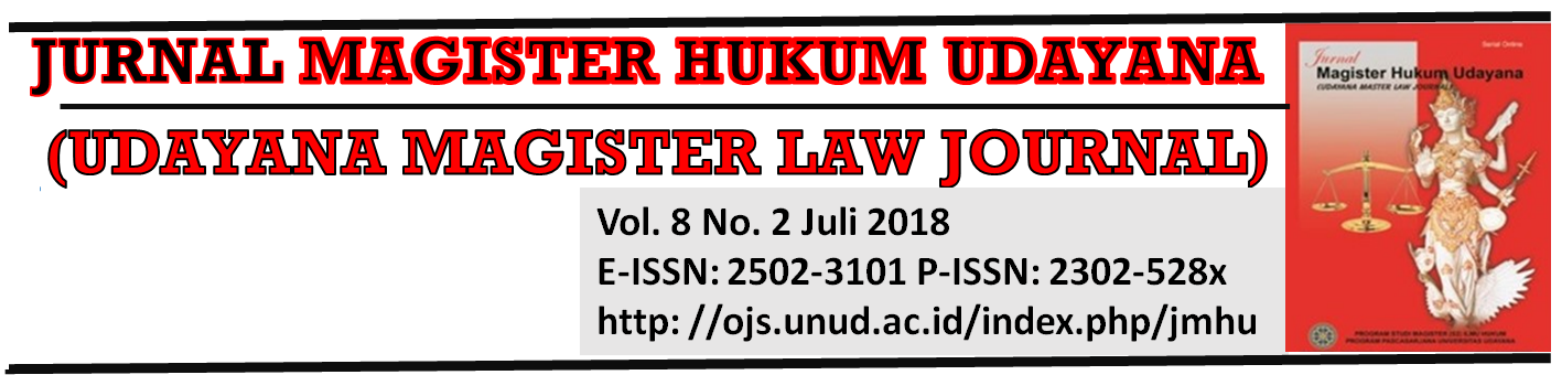

\title{
Implikasi Hukum Paris Agreement Melalui Program REDD+ Berbasis Blue Carbon Di Indonesia
}

\section{Elda Sofia ${ }^{1}$}

${ }^{1}$ Fakultas Hukum Universitas Andalas, E-mail: sofiaelda24@gmail.com

\begin{tabular}{l}
\hline Info Artikel \\
\hline Masuk: 4 Maret 2019 \\
Diterima: 9 Mei 2019 \\
Terbit: 31 July 2019 \\
Keywords: \\
Paris Agreement; REDD+; Blue \\
Carbon
\end{tabular}

Kata kunci:

Persetujuan Paris; REDD+;

Karbon Biru

Corresponding Author:

Elda Sofia, E-mail:

sofiaelda24@gmail.com

DOI:

10.24843/JMHU.2019.v08.i02.p 03

\begin{abstract}
To replace the Kyoto Protocol to the UNFCCC post-2020 the Participating Countries of UNFCCC made a new commitment namely Paris Agreement to the UNFCCC. Indonesia has ratified the Paris Agreement to become its national law. In Paris Agreement to the UNFCCC, all Countries should reduce greenhouse gas/GHG emissions following the principle of common but differentiated responsibilities. GHG emissions reductions obligations are set out in a nationally determined contribution/NDC. Within the NDC, Indonesia achieves emission reduction greenhouse gas targets up to $29 \%$ on its own and up $41 \%$ with international assistance. GHG emissions reductions through the forestry sectors are key sectors in NDC Indonesia at $17.2 \%$. Using the method of normative research through an approach to legislation. After ratified of Paris Agreement to the UNFCCC brings legal implications for Indonesia namely the establishment of the laws on REDD+ in the forestry sector. Efforts made by the government of Indonesia is the establishment of the laws on REDD+. It has found the legal problem which can be a factor inhibiting the achievement of NDC target consisting of law enforcement, legal certainty of forest area. It is suggested that the Government of Indonesia makes regulation on mangrove forest.

\begin{tabular}{l}
\hline Abstrak \\
\hline Untuk menggantikan Kyoto Protocol pasca 2020 Negara Peserta \\
UNFCCC membuat komitmen baru yaitu Paris Agreement to the \\
UNFCCC. Indonesia telah meratifikasi Paris Agreement menjadi \\
hukum nasional. Di dalam Paris Agreement to the UNFCCC, \\
semua negara diberikan kewajiban untuk mengurangi emisi gas \\
rumah kaca sesuai dengan prinsip common but differentiated \\
responsibilities. Kewajiban pengurangan emisi gas rumah kaca \\
ditetapkan dalam nationally determined contribution/NDC. Di \\
dalam NDC, Indonesia mempunyai target untuk mengurangi \\
emisi gas rumah kaca sebesar $29 \%$ dengan usaha sendiri dan \\
sampai dengan $41 \%$ dengan bantuan internasional. Pengurangan \\
emisi gas rumah kaca melalui sektor kehutanan adalah sektor \\
utama dalam NDC Indonesia yaitu sebesar 17.2\%. Metode \\
penelitian yang digunakan adalah penelitian hukum normatif \\
yaitu melalui pendekatan perundang-undangan. Pasca \\
diratifikasinya Paris Agreement to the UNFCCC membawa \\
implikasi hukum bagi Indonesia yaitu dibentuknya sejumlah \\
peraturan-peraturan terkait REDD+ di sektor kehutanan. Upaya- \\
upaya yang dilakukan pemerintah Indonesia untuk \\
mengimplementasikan Paris Agreement to the UNFCCC sektor
\end{tabular}
\end{abstract}


kehutanan adalah membentuk sejumlah peraturan-peraturan hukum terkait REDD+. Persoalan-persoalan hukum yang ditemui menjadi faktor penghambat tercapainya target NDC Indonesia yaitu penegakan hukum, kepastian hukum kawasan hutan. Disarankan agar dibentuknya regulasi tentang perlindungan terhadap hutan mangrove.

\section{Pendahuluan}

Pada prosesnya perubahan iklim terjadi karena iklim di bumi sebagian besar dipengaruhi oleh kehadiran gas rumah kaca/GRK alami di atmosfer. Di samping GRK alami dikenal juga GRK antropogenis (man-made greenhouse gases) yakni gas yang merupakan produk sampingan (by products) dari kegiatan manusia, GRK termasuk ke dalamnya adalah karbon dioksida/CO2, metana/CH4, chloro fluoro carbons/CFCs, nitrogen dioksida/N2O, dan ozon troposfer/O3. ${ }^{1}$ Bukti ilmiah telah menunjukkan bahwa jumlah gas rumah kaca terus mengalami kenaikan karena ulah manusia di bumi yang kemudian mengarah pada terjadinya efek gas rumah kaca dan perubahan iklim global. ${ }^{2}$ Pada laporan IPCC pertama yang di publikasikan pada Agustus 1990 menyatakan jika skenario biasa masih tetap diberlakukan (business as usual), Maksudnya jika tidak melakukan tindakan apapun untuk menangani masalah lingkungan tersebut, maka suhu rata-rata global akan terus mengalami kenaikan sekitar $0,3^{\circ} \mathrm{C}$ per dekade. Hal ini menjadikan kenaikan suhu rata-rata global sekitar $2^{\circ} \mathrm{C}$ pada tahun 2025 dan sekitar $4^{\circ} \mathrm{C}$ pada tahun $2100.3^{3}$

Untuk menanggapi hal itu pada Desember 1990, Majelis Umum PBB mendirikan Intergovermental Negotiating Committee/INC (Komite Negosiasi Antar Pemerintah untuk menegosiasikan konvensi untuk mencegah perubahan iklim). Kemudian pada sidangnya yang kelima Mei 1992, INC berhasil mengadopsi sebuah kerangka hukum yaitu united nations framework convention on climate change/ UNFCCC. ${ }^{4}$ Dalam UNFCCC mengandung prinsip yang harus dipegang oleh semua pihak untuk mencapai tujuan akhir UNFCCC yaitu Common but Differentiated Responsibilities Principle.

Dalam UNFCCC Negara anggota dibagi menjadi 3 kelompok utama yaitu : ${ }^{5}$

1) Negara-negara Annex I yaitu negara-negara maju yang merupakan anggota dari kerja sama dan pembangunan ekonomi atau Organization for Economic Co-operation and Development /OECD pada tahun 1992, dan negara-negara yang ekonominya masih dalam peralihan menjadi negara maju.

2) Negara-negara Annex II terdiri dari negara-negara maju yang masuk dalam Annex 1 yang menjadi anggota dari kerja sama dan pembangunan ekonomi.

1 Husin, S. (2016). Hukum Internasional dan Indonesia tentang Perubahan Iklim. Jakarta: PT.Rajagrafindo Persada, h. 2

2 Sands, P. (2003). Principles Of International Environmental Law, Second Edition. New York: Cambridge University Press, p. 357-358

3 Ibid., p. 358

4 Ibid., p. 359

5 United Nation Climate Change. Parties \& Observers.. Retrieved from https://unfccc.int/parties-observers 
3) Negara-negara Non-Annex 1 terdiri dari negara-negara berkembang, negaranegara dengan dataran pesisir pantai yang rendah, negara-negara yang rentan terhadap terjadinya penggurunan dan kekeringan. Dan, 49 pihak negara yang tergolong Less-Developed Countries/ LDCs.

The UNFCCC tidak memutuskan angka-angka pengurangan, maka untuk melahirkan angka-angka pengurangan (regulatory measures) negara anggota membuat Kyoto Protocol to the UNFCCC yang diadopsi pada Conference Of the Parties/ COP ke-3 pada bulan Desember 1997. Dibentuknya Kyoto Protocol adalah amanat dari Article 17 UNFCCC. Adapun tujuan dibentuknya Kyoto Protocol dimuat pada Pasal 3 (1) Kyoto Protocol yang berisi komitmen yang memberikan kewajiban bagi negara-negara maju baik secara individu atau bersama-sama untuk membatasi dan menurunkan emisi gas rumah kacanya (CO2, CH4, N2O, HFCs, PFCs, SF6). Jumlah pembatasan terhadap emisi gas rumah kaca itu dimuat dalam Annex B Kyoto Protocol. Negara maju pada tahun 2008-2012 wajib memasukkan pada tahun dasarnya 1990 berupa sumber penyerapan emisi $\mathrm{CO} 2, \mathrm{CH} 4$, dan $\mathrm{N} 2 \mathrm{O}$ yang bertujuan untuk penghitungan jumlah yang ditetapkan bagi negara maju. ${ }^{6}$ Kemudian, tahun 1995 sebagai tahun dasar penghitungan jumlah untuk HFCs, PFCs, dan SF6. ${ }^{7}$ Sementara itu bagi negara berkembang tidak diwajibkan untuk melakukan pengurangan emisi gas rumah kaca sebagaimana halnya yang ditetapkan Pasal 3 (1) Kyoto Protocol.

Oleh karena masa berlaku Kyoto Protocol pertama telah berakhir maka berdasarkan Article 3 (9) Kyoto Protocol yaitu komitmen untuk periode berikutnya untuk para pihak harus diadopsi dan wajib diajukan pada COP sekurang-kurangnya 7 tahun sebelum akhir periode komitmen I. Barulah pada COP ke-8, 8 Desember 2012 melalui Doha Amandment to The Kyoto Protocol dikeluarkan keputusan komitmen baru untuk pihak Annex 1 Kyoto Protocol untuk melakukan komitmen II Kyoto Protocol dalam periode dari 1 Januari 2013 sampai 31 Desember 2020. Pada Kyoto Protocol komitmen II, para pihak termasuk Annex 1 diminta untuk menurunkan emisi gas rumah kaca mereka ,8 hingga sekurang-kurangnya 18 persen, ${ }^{9}$ dimana tahun 1990 sebagai tahun dasar patokan pengurangan emisi gas rumah kaca dalam periode 8 tahun dari tahun 20132020.10 Untuk melanjutkan Kyoto Protocol maka negara anggota membuat komitmen baru yaitu Paris Agreement to the UNFCCC yang berhasil dirumuskan pada COP-21 UNFCCC tahun 2015 di Paris.

Dengan diratifikasinya Paris Agreement To The UNFCCC oleh Indonesia, maka berdasarkan prinsip pacta sunt servanda telah menjadikan Indonesia terikat secara hukum pada Paris Agreement. Maka untuk mengimplementasikan Paris Agreement berdasarkan prinsip Common but Differentiated Responsibilities Indonesia turut dalam

6 Article 3 ( 7 ) Kyoto Protocol to the UNFCCC

7 Article 3 ( 8 ) Kyoto Protocol to the UNFCCC

8 Pada Kyoto Protokol komitmen I gas rumah kaca terdiri atas CO2, CH4, N2O,HFC5, PFC5, SF6. Pada Kyoto Protokol komitmen II, gas rumah kaca ditambah satu yaitu NF3/ Nitrogentrifluoride, termuat dalam Article 1: Amandment (B) Doha Amandment to the Kyoto Protocol

9 Pada Kyoto Protokol komitmen I, para pihak Annex 1 konvensi diwajibkan untuk mengurangi emisi gas rumah kaca sekurang-kurangnya 5 persen secara keseluruhan pada tingkat tahun 1990 sebagaimana yang terlampir dalam Annex B KyotoProtokol. Sementara itu, pada Kyoto Protokol komitmen II, jumlah pengurangan emisi menjadi 18 persen

${ }^{10}$ Article 1 : Amandment (C) Doha Amandment to the Kyoto Protocol 
melaksanakan komitmen-komitmen yang telah diatur dalam Paris Agreement dalam memerangi perubahan iklim. Sebagai bentuk tindak lanjut Paris Agreement seluruh negara anggota wajib melakukan upaya yang ambisius untuk memerangi perubahan iklim yang ditetapkan dalam Nationally Determined Contribution/ NDC. NDC adalah bentuk komitmen yang berisi kontribusi masing-masing negara anggota yang ditetapkan secara nasional untuk mengurangi gas rumah kacanya. Indonesia telah menetapkan first NDC sejak November 2016 ke Badan Sekretariat UNFCCC. NDC Indonesia meliputi upaya mitigasi Indonesia untuk mengurangi emisi gas rumah kaca sebesar 29\% dengan usaha sendiri dan $41 \%$ dengan usaha kerjasama internasional pada tahun 2030. Ada 5 sektor yang termuat dalam NDC yaitu sektor kehutanan sebesar $17,2 \%$, sektor energi sebesar $11 \%$, sektor pertanian sebesar $0,32 \%$, sektor industri sebesar $0,10 \%$ dan sektor limbah sebesar $0,38 \% .{ }^{11}$

Sektor hutan dan lahan di Indonesia merupakan sektor yang menyumbangkan emisi sekaligus mempunyai potensi penurunan emisi yang besar. Melihat kondisi ini, Indonesia memiliki komitmen yang jelas untuk menempatkan posisi REDD+ sebagai usaha utama dalam pencapaian komitmennya. REDD+ adalah sebuah mekanisme insentif internasional yang bertujuan untuk mendorong kebijakan dan tindakan di negara-negara berkembang pemilik hutan untuk mengurangi deforestasi dan degradasi hutan. REDD+ terfokus pada permasalahan hutan yaitu bagaimana pengelolaan hutan dilakukan dalam rangka mereduksi emisi $\mathrm{CO} 2$ melalui upaya pengurangan dan pencegahan deforestasi dan degradasi hutan dan atau perlindungan hutan untuk meningkatkan kuantitas tutupan hutan atau stock carbon, diberi simbol $(+)$ karena termasuk di dalamnya adalah upaya konservasi dan pengelolaan hutan secara berkelanjutan. ${ }^{12}$

Paris Agreement menyebutkan REDD+ secara eksplisit, yaitu di Pasal 5 Paragraf 1 yang menyebutkan bahwa semua negara harus mendukung penurunan emisi, dan Paragraf 2 dimana $R E D D+$ harus menjadi bagian penting dari penurunan emisi tersebut termasuk implementasi dan support melalui result based payment. ${ }^{13}$ REDD+ diimplementasikan untuk menekan laju terjadinya deforestasi dan degradasi pada hutan, meningkatkan penanaman dan penyerapan GRK, serta penyerapan GRK dari hutan mangrove atau hutan pantai. Ekosistem mangrove atau hutan bakau termasuk ekosistem pantai atau komunitas bahari dangkal yang sangat menarik, yang terdapat pada perairan tropik dan suptropik. ${ }^{14}$ Penyerapan GRK dari hutan mangrove atau hutan pantai inilah yang disebut dengan Blue Carbon. Adapun kuantitas dari tanaman

${ }_{11}$ United Nation Climate Change. Indonesia INDC. Retrieved from http://unfccc.int/ndcregistry/publisheddocuments/indonesiafirst/firstNDCindonesia_sub mittedtoUNFCCC

12 Widjaksono, A.G, MAS. (2016). Prosiding "REDD+ Indonesia Day" Seminar Nasional dan Pameran Bersama, "Moving REDD+ Indonesia Forward : Resolving Challenges-Seri II: Instrumen Pendanaan. Jakarta: Direktorat Jenderal Pengendalian Perubahan Iklim Kementerian Lingkungan Hidup dan Kehutanan, h. 19

${ }^{13}$ Sari, A.P. (2016). Prosiding "REDD+ Indonesia Day" Seminar Nasional dan Pameran Bersama, "Moving REDD+ Indonesia Forward : Resolving Challenges-Seri II : Stranas dan Srap/Strada REDD+ dan Implikasi Paris Agreement: Quo Vadis REDD+ After Paris ?. Jakarta: Direktorat Jenderal Pengendalian Perubahan Iklim Kementerian Lingkungan Hidup dan Kehutanan, h. 11

${ }^{14}$ Djamal Irwan, Z. (2014). Prinsip-Prinsip Ekologi Ekosistem, Lingkungan dan Pelestariannya, Jakarta: PT.Bumi Aksara, h. 135 
mangrove itu sendiri adalah mangrove berfungsi sebagai penyerap karbon dioksida yaitu melalui proses fotosintesis, mangrove berfungsi sebagai penyimpan karbon dioksida/ carbon sinks, sebagian besar karbon dioksida disimpan di dalam tanah dibawah hutan mangrove.

Indonesia adalah negara kepulauan dengan pesisir pantai yang panjang sehingga mempunyai hutan mangrove paling luas di dunia. Pada tahun 2006 luas hutan mangrove Indonesia adalah seluas 4,3 juta hektar. Pada tahun 2005 luas hutan mangrove Indonesia adalah seluas 3.062.300 hektar, ini merupakan bagian $19 \%$ dari total luas hutan mangrove di seluruh dunia. ${ }^{15}$ Hutan mangrove di Indonesia tersebar di setiap provinsi di Indonesia, luas terbesar pada tahun 2016 terdapat di provinsi Papua yaitu 1,1 juta hektar atau 29,05\% dari luas mangrove di Indonesia. Sedangkan luas mangrove terkecil terdapat di provinsi DI Yogyakarta yaitu 40,10 hektar. Luas hutan mangrove Indonesia tahun 2014 adalah 4,4 juta hektar, tahun 2015 adalah 3,7 juta hektar dan tahun 2016 adalah 3,9 juta hektar. Kerusakan mangrove tahun 2016 sebesar 52\%. Kerusakan terbesar terdapat pada provinsi Sulawesi Selatan. ${ }^{16} \mathrm{Hal}$ ini akan menjadi pekerjaan besar bagi Pemerintah Indonesia dalam menyikapi kondisi luas hutan mangrove yang cenderung fluktuatif. Hutan mangrove yang luas sebarannya tidak merata di setiap provinsi di Indonesia, dimana perhatian pemerintah tidak saja pada provinsi dengan luas hutan mangrove yang paling luas namun juga pada luas hutan mangrove terkecil sekalipun bagaimana ekosistem mangrove lebih ditingkatkan jumlah luasnya dan mengurangi terjadinya faktor-faktor yang dapat mengganggu dalam kelangsungan ekosistem mangrove. Mengingat hutan mangrove termasuk sebagai Blue Carbonnya Indonesia mempunyai peranan yang sangat penting dalam upaya pencapaian target NDC. Namun berdasarkan hasil penelitian Paris Agreement yang disahkan melalui Undang-Undang Nomor 16 tahun 2016 sejak diundangkannya undang-undang tersebut maka secara hukum Paris Agreement telah berlaku di Indonesia dan menjadi hukum positif di Indonesia. Persoalan hukum yang ditemui dalam pelaksanaan program REDD+ berbasis blue carbon di Indonesia adalah penegakan hukum yang masih lemah dan kepastian hukum berupa perangkat hukum dalam hal perlindungan dan pengelolaan terhadap hutan mangrove. Berdasarkan latar belakang tersebut diatas yang menjadi permasalahan adalah : 1) Apa implikasi hukum Paris Agreement bagi Indonesia ? 2) Apakah persoalan hukum yang dihadapi oleh Indonesia dalam melaksanakan program REDD+ berbasis blue carbon?.

Tujuan penulisan ini adalah untuk menjelaskan apa implikasi hukum diratifikasinya Paris Agreement to the UNFCCC bagi hukum nasional Indonesia dan untuk menjelaskan persoalan hukum yang dihadapi Indonesia dalam melaksanakan program REDD+ berbasis Blue Carbon.

\section{Metodologi Penelitian}

Penelitian ini menggunakan metode penelitian hukum normatif (yuridis normative) yaitu penelitian yang bertujuan untuk meneliti asas-asas hukum, sistematika hukum, sinkronisasi hukum, sejarah hukum dan perbandingan hukum, ${ }^{17}$ dengan kata lain penelitian hukum normatif diartikan juga sebagai penelitian yang dilakukan dengan

\footnotetext{
15 Statistik Sumber Daya Laut dan Pesisir. (2017). Jakarta: Badan Pusat Statistik, h. 23

16 Ibid., h. 23

17 Soekanto, S. (2008). Pengantar Penelitian Hukum. Jakarta: Universitas Indonesia Press, h. 51
} 
cara meneliti bahan-bahan pustaka atau data sekunder belaka. ${ }^{18}$ Pendekatan masalah yang digunakan dalam penulisan ini melalui pendekatan berbagai peraturan perundang-undangan (statute approach).

\section{Hasil dan Pembahasan}

\subsection{Implikasi hukum Paris Agreement to the UNFCCC terhadap Indonesia}

Sebagaimana diketahui ciri hukum keras pada hukum internasional adalah bahwa konvensi itu mempunyai kekuatan mengikat (binding power) pada negara-negara peserta konvensi. Demikian halnya dengan Paris Agreement berbentuk hard law with hard regulations, yang mempunyai kekuatan mengikat dan memuat kewajibankewajiban dan larangan-larangan bagi negara-negara Pihak.

Tujuan negara-negara untuk membuat Paris Agreement karena adanya suatu kehendak bersama dari negara-negara. Hal ini merupakan bentuk perwujudan dari teori hukum internasional yang dikenal dengan teori kehendak bersama negara-negara. Negaranegara tersebut telah menyepakati dan menyetujui untuk terikat pada Paris Agreement. Sebagai konsekuensinya setiap negara peserta harus mentaati dan menghormati Paris Agreement.

Daya mengikat Paris Agreement didasarkan pada prinsip hukum internasional pacta sunt servanda. Dasar hukum pacta sunt servanda diatur pada Pasal 26 Konvensi Wina tahun 1969 tentang Hukum Perjanjian, dalam Pasal 26 pacta sunt servanda berarti tiaptiap perjanjian yang berlaku mengikat negara-negara yang menjadi anggota perjanjian dan harus dilaksanakan dengan itikad baik.

Sebagai bentuk implikasi terhadap Indonesia sebagai negara anggota Paris Agreement menjadikan Indonesia terikat pada Paris Agreement, dan wajib mentaati dan menghormati Paris Agreement. Melaksanakan kewajiban-kewajiban yang termuat dalam Paris Agreement. Dalam pelaksanaan Paris Agreement, Indonesia sebelumnya telah melalui proses persetujuan untuk terikat pada Paris Agreement. Menurut Pasal 1 butir b Konvensi Wina 1969, pengikatan diri atau persetujuan untuk terikat dapat dilakukan dengan cara ratifikasi, aksesi, penerimaan atau akseptasi, dan persetujuan.

Pada Paris Agreement setiap negara diwajibkan mengurangi dan membatasi emisi gas rumah kacanya, maka bentuk komitmen masing-masing negara dituangkan dalam nationally determined contribution. Paris Agreement memuat kewajiban-kewajiban yang tersirat pada Article 4 (2) (9) (13), Article 13 (7) huruf a,b. Menurut Article 4 memuat kewajiban semua negara untuk melaksanakan dan menetapkan NDC sebagai bentuk komitmen masing-masing negara melalui upaya mitigasi, untuk mencapai target dalam NDC-nya, melaporkan hasil capaian NDC-nya setiap lima tahun, dan bertanggung jawab terhadap pelaksanaan NDC-nya. Menurut Article 13 (7) huruf a,b memuat kewajiban semua negara untuk melaporkan hasil inventarisasi gas rumah kaca secara nasional secara berkala dan laporan terkait informasi kemajuan pelaksanaan NDC.

${ }^{18}$ Soekanto, S., \& Mamudji, S. (2006). Penelitian Hukum Normatif; Suatu Tinjauan Singkat. Jakarta: Rajawali Pers, h. 13-14 
Paris Agreement berdasarkan pada prinsip common but differentiated responsibilities yang didasarkan pada tanggung jawab semua negara untuk mengurangi emisi rumah kacanya namun disesuaikan dengan kondisi nasional setiap negara anggota. Paris Agreement memberikan kewajiban kepada negara maju untuk memimpin pelaksanaan Paris Agreement baik itu dalam hal penyediaan dana, alih teknologi dan meningkatkan kapasitas bagi negara-negara berkembang.

Ratifikasi merupakan bentuk persetujuan suatu negara untuk mengikatkan diri pada perjanjian internasional. Menurut F.O Wilcox mengenai ratifikasi menyatakan :

"Ratification is an expression of consent whereby the state assumes the right and duties imposed by the instrument ratification."

Disini Wilcox menekankan bahwa persetujuan yang diberikan mengakibatkan suatu negara mempunyai hak-hak dan kewajiban yang tercantum dalam perjanjian itu. ${ }^{19}$

Paris Agreement telah disahkan menjadi hukum nasional Indonesia yaitu melalui Undang-Undang Nomor 16 tahun 2016 tentang Pengesahan Paris Agreement to the UNFCCC, setelah sebelumnya ditandatangani oleh pemerintah Indonesia pada tanggal 22 April 2016 di New York, Amerika Serikat. Berlakunya Paris Agreement melalui undang-undang adalah melalui pengesahan yang dilakukan oleh Presiden yang sebelumnya rancangan undang-undang pengesahan tersebut telah disetujui dan dibahas bersama oleh DPR dan Presiden. Dengan demikian Paris Agreement itu akan berlaku dan menjadi bagian dari hukum nasional Indonesia, dan telah berlaku terhitung sejak Undang-Undang Nomor 16 tahun 2016 diundangkan yaitu pada tanggal 25 Oktober 2016.

Dari pernyataan diatas dapat dikatakan bahwa implikasi hukum dari Paris Agreement terhadap Indonesia adalah dengan diratifikasinya Paris Agreement oleh Indonesia dan disahkan dengan undang-undang menjadikan Paris Agreement adalah bagian dari hukum positif di Indonesia dan berimplikasi langsung timbulnya hak-hak serta kewajiban-kewajiban sesuai dengan yang termuat dalam Paris Agreement.

Pada dasarnya setiap orang yang hidup di bumi ini berhak untuk hidup aman dan terhindar dari bahaya terjadinya perubahan iklim. Hak ini merupakan hak universal bagi manusia, hal ini diatur dalam konstitusi Indonesia. Pasal $28 \mathrm{H}$ ayat 1 dalam konstitusi menyebutkan bahwa setiap orang berhak hidup sejahtera lahir dan bathin, bertempat tinggal, dan mendapatkan lingkungan hidup yang baik dan sehat serta berhak memperoleh pelayanan kesehatan.

Berdasar pada prinsip common but differentiated responsibilities yang diimplementasikan dalam Paris Agreement maka Pihak negara berkembang termasuk Indonesia berhak mendapatkan sumber pendanaan yang disediakan oleh pihak negara maju, dan berhak mendapatkan informasi yang jelas, terbuka serta konsisten terkait dukungan untuk negara berkembang setiap dua tahun. Ditambahkan juga, dukungan ini termasuk dukungan keuangan yang wajib disediakan oleh Pihak negara maju kepada pihak negara berkembang termasuk penguatan kerja sama dalam hal pengembangan dan alih teknologi.

${ }^{19}$ Edy, S. (1988). Praktek Ratifikasi Perjanjian Internasional di Indonesia. Bandung: Remadja Karya, h. 26 
Indonesia sebagai negara anggota Paris Agreement secara otomatis menjadi bagian dari anggota Conference of the Parties yang bersidang setiap tahunnya mengkaji pelaksanaan Paris Agreement dan wajib menetapkan keputusan untuk mendorong pelaksanaan Paris Agreement yang efektif. Indonesia sebagai pihak dalam Paris Agreement berhak memiliki satu suara dalam setiap sidang Konferensi Para Pihak. Maka dalam hal ini, Indonesia dapat menyampaikan aspirasi dan memberi pengaruh pada setiap keputusan yang dihasilkan oleh Konferensi Para Pihak, hal ini juga didasarkan dengan memperhatikan keputusan yang membawa dampak yang positif bagi Indonesia dan rakyat Indonesia.

Adapun kewajiban utama yang telah dilakukan Indonesia adalah kewajiban menyampaikan nationally determined contribution. Indonesia telah menetapkan first Nationally Determined Contribution/ NDC sejak November 2016 ke Badan Sekretariat UNFCCC. NDC Indonesia meliputi upaya mitigasi Indonesia untuk mengurangi emisi gas rumah kaca sebesar 29\% dengan usaha sendiri dan $41 \%$ dengan usaha kerjasama internasional pada tahun 2030. Ada 5 sektor yang termuat dalam NDC yaitu sektor kehutanan sebesar $17,2 \%$, sektor energi sebesar $11 \%$, sektor pertanian sebesar $0,32 \%$, sektor industri sebesar $0,10 \%$ dan sektor limbah sebesar $0,38 \% .{ }^{20}$

Dalam NDC Indonesia itu, sektor kehutanan merupakan sektor utama bagi Indonesia untuk mencapai NDC. Sebagaimana yang tersirat dalam Article 5 Paris Agreement, setiap negara dihimbau untuk melakukan tindakan konservasi dan meningkatkan serapan karbon dan penyimpanan karbon. Mengingat hal ini, maka Indonesia menjadikan kegiatan $R E D D+$ menjadi bagian dari sektor kehutanan untuk mencapai NDC.

Implikasi hukum Paris Agreement terhadap Indonesia setelah mengesahkan Paris Agreement adalah pembentukan peraturan pelaksana yang memuat isi untuk mengimplementasikan Paris Agreement oleh Pemerintah. Maka sejumlah peraturan pelaksana dibentuk oleh KemenLHK yang ditunjuk oleh Presiden sebagai national focal point atau lembaga utama yang mengurus terkait perubahan iklim. Dibentuknya Peraturan Presiden Nomor 16 tahun 2015 merupakan bentuk persiapan Indonesia untuk mengimplementasikan Paris Agreement. Melalui Perpres ini KemenLHK diberikan tugas oleh Presiden untuk menyelenggarakan urusan pemerintahan di bidang lingkungan hidup dan kehutanan. Dengan ini Perpres ini sekaligus mencabut peraturan yang mengatur tentang Badan Pengelola REDD dan lembaga dewan nasional perubahan iklim. Sejumlah peraturan pelaksana itu juga merupakan peraturan pelaksana dibawah Undang-Undang Nomor 32 tahun 2009 tentang Perlindungan dan Pengelolaan Lingkungan Hidup dan Undang-undang Nomor 41 tahun 1999 tentang Kehutanan.

Peraturan Menteri Lingkungan Hidup dan Kehutanan Nomor P.70 tahun 2017 tentang Tata Cara Pelaksanaan Reducing Emissions from Deforestation and Forest Degradation, Role of Conservation, Sustainable Management of Forest and Enhancement of Forest Carbon Stocks dibentuk untuk mengimplementasikan Paris Agreement. Peraturan ini merupakan amanat dari Article 5 Paris Agreement terkait

${ }^{20}$ United Nation Climate Change. Indonesia INDC. Retrieved from http://unfccc.int/ndcregistry/publisheddocuments/indonesiafirst/firstNDCindonesia_sub mittedtoUNFCCC 
$R E D D+$. Tujuan peraturan ini adalah untuk tercapainya pelaksanaan $R E D D+$ yang sesuai dengan persyaratan keputusan COP UNFCCC tentang REDD+ dan konsisten dengan kebijakan nasional, serta mendorong pelaksanaan $R E D D+$ untuk menuju pelaksanaan REDD+ secara penuh (result based payment), untuk mendukung pancapaian target implementasi NDC sektor kehutanan.

\subsection{Persoalan hukum yang dihadapi Indonesia dalam melaksanakan program REDD+ berbasis Blue Carbon}

Sejak diratifikasinya Paris Agreement dan disusul dengan penetapan first NDC adalah bentuk keseriusan pemerintah Indonesia dalam memerangi perubahan iklim.

Berikut tabel NDC Indonesia

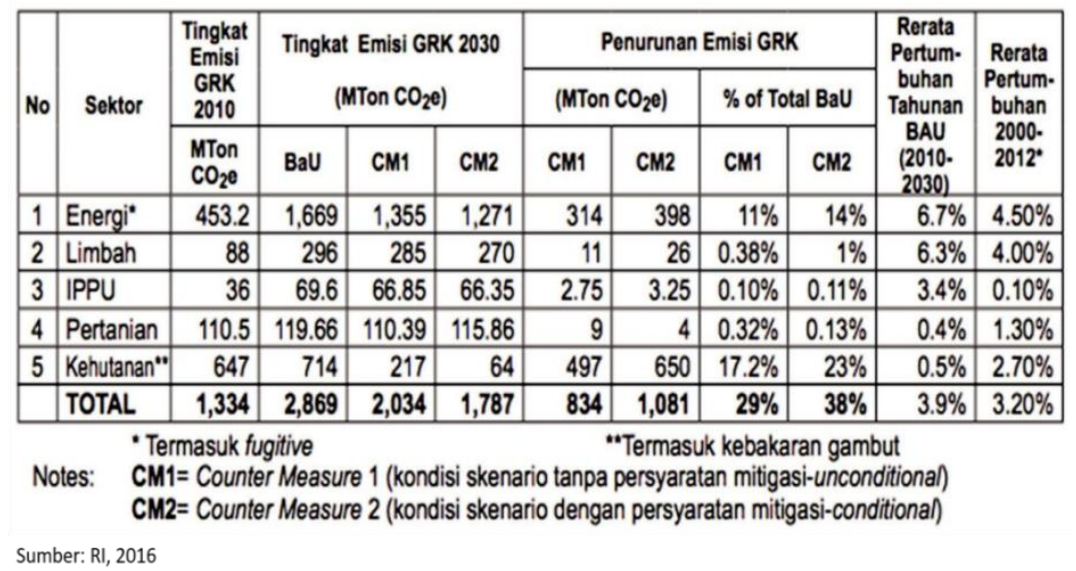

Dalam tabel NDC diatas dimuat tentang lima kategori sektor dan proporsi kontribusinya dalam upaya penurunan emisi gas rumah kaca sebesar $29 \%$ dengan upaya sendiri yang ditargetkan akan dicapai pada tahun 2030, yakni : kehutanan $(17,2 \%)$, energi $(11 \%)$, pertanian $(0,32 \%)$, industri $(0,10 \%)$, dan limbah $(0,38 \%)$. Hutan mangrove sudah masuk dalam total perhitungan kawasan hutan dalam sektor agriculture, forestry and other land use (AFOLU) untuk sektor NDC Indonesia. Dan berupaya menurunkan emisi gas rumah kaca hingga $40 \%$ dengan bantuan atau dukungan internasional. ${ }^{21}$ Ketetapan yang dituangkan dalam NDC tersebut adalah bentuk kesiapan Indonesia untuk mengimplementasikan Paris Agreement. Penurunan emisi gas rumah kaca yang ditargetkan oleh Indonesia pada sektor kehutanan adalah sebesar 17,2\% yang akan dicapai pada tahun 2030.

Konsep REDD+ adalah untuk mengurangi emisi karbon dioksida melalui upaya pengurangan dan pencegahan deforestasi dan degradasi hutan dan atau perlindungan hutan untuk meningkatkan kuantitas tutupan hutan atau stock carbon, serta dengan upaya konservasi dan pengelolaan hutan secara berkelanjutan. Konsep REDD+ boleh berlaku untuk semua jenis hutan di Indonesia. Dalam pasal 6 Undang-Undang Nomor 41 tahun 1999 tentang Kehutanan menyebutkan hutan mempunyai tiga fungsi yaitu fungsi konservasi, fungsi lindung, dan fungsi produksi. Kawasan hutan inilah yang menjadi bagian konsep REDD+ sebagaimana yang diatur dalam Paris Agreement.

${ }^{21}$ Kementerian Lingkungan Hidup dan Kehutanan. (2017). Summary Nationally Determined Contribution (NDC) dan Progres, Jakarta, h. 9 
Laut mempunyai peran sebagai pengikat karbon (blue carbon), blue carbon adalah penyerapan gas karbon dioksida oleh tanaman yang hidup di laut. Ekosistem yang kaya akan tanaman seperti hutan mangrove, padang lamun dan rawa payau/hutan gambut yang mampu menyerap sejumlah karbon di atmosfer. Hutan mangrove mampu mengurangi karbon dioksida melalui mekanisme sekuestrasi yaitu penyerapan karbon dari atmosfer dan penyimpanannya dalam beberapa komparlemen seperti tumbuhan, serasah, dan bahan organik tanah melalui proses fotosintesis, karbon dioksida akan diserap oleh tumbuhan mangrove dan diubah menjadi karbon organik yang didistribusikan ke seluruh bagian tubuh tumbuhan dan disimpan dalam biomassa, pada dasarnya hampir 50\% biomassa pohon adalah karbon yang tersimpan, tumbuhan mangrove menyerap sebagian karbon dalam bentuk karbon dioksida yang dimanfaatkan untuk proses fotosintesis sedangkan sebagian lainnya tetap berada di atmosfer. ${ }^{22}$

Indonesia adalah Negara kepulauan dengan pesisir pantai yang panjang sehingga mempunyai hutan mangrove paling luas di dunia. Pada tahun 2006 luas hutan mangrove Indonesia adalah seluas 4,3 juta hektar. Pada tahun 2005 luas hutan mangrove Indonesia adalah seluas 3.062.300 hektar, ini merupakan bagian $19 \%$ dari total luas hutan mangrove di seluruh dunia. ${ }^{23}$ Hutan mangrove di Indonesia tersebar di setiap provinsi di Indonesia, luas terbesar pada tahun 2016 terdapat di provinsi Papua yaitu 1,1 juta hektar atau 29,05\% dari luas mangrove di Indonesia. Sedangkan luas mangrove terkecil terdapat di provinsi DI Yogyakarta yaitu 40,10 hektar. Luas hutan mangrove Indonesia tahun 2014 adalah 4,4 juta hektar, tahun 2015 adalah 3,7 juta hektar dan tahun 2016 adalah 3,9 juta hektar. Kerusakan mangrove tahun 2016 sebesar $52 \%$. Kerusakan terbesar terdapat pada provinsi Sulawesi Selatan. ${ }^{24}$

Salah satu penyebab kerusakan mangrove berasal dari aktivitas manusia. Aktivitas manusia yang menyebabkan kerusakan mangrove adalah pembukaan lahan untuk tambak ikan, garam, dan udang, pemukiman, pertanian, pertambangan, dan perindustrian, serta perambahan mangrove secara berlebihan misalnya untuk pembuatan arang, kayu bakar, dan bahan bangunan. ${ }^{25}$ Ancaman utama kerusakan mangrove dapat terjadi secara langsung maupun tidak langsung. Ancaman secara langsung adalah adanya peningkatan pembangunan di wilayah pesisir misalnya pemanfaatan untuk budidaya perairan, pertanian, industri, infrastruktur pantai termasuk pelabuhan, serta pembangunan tempat perdagangan dan perumahan. Sedangkan ancaman secara tidak langsung berasal dari luar yang disebabkan oleh aktivitas yang terdapat jauh dari habitat mangrove. Misalnya pengelolaan daerah aliran sungai (DAS) yang serampangan, pencemaran hasil industri dan domestik atau rumah tangga yang masuk dalam daur hidrologi, erosi, tanah, dan sedimentasi yang tinggi. Akibat dari aktifitas itu akan berakibat kematian massal terhadap mangrove. ${ }^{26}$

Melihat kondisi ini, luas mangrove di Indonesia cenderung fluktuatif dari tahun ke tahun. Luas hutan mangrove tahun 2014 adalah 4,4 juta hektar, pada tahun 2015 adalah 3,7 juta hektar dan pada tahun 2016 adalah 3,9 juta hektar. Kerusakan pada

\footnotetext{
22 Baderan, D.W.K. (2017). Serapan Hutan Mangrove Gorontalo. Yogyakarta: Deepublish, h. 3

${ }^{23}$ Statistik Sumber Daya Laut dan Pesisir. (2017). Jakarta: Badan Pusat Statistik , h. 23

${ }^{24}$ Ibid., h. 23

${ }^{25}$ Ibid., h. 24

${ }^{26}$ Ibid., h. 24
} 
mangrove tahun 2016 sebesar 52\%. Kerusakan terbesar terdapat pada provinsi Sulawesi Selatan. ${ }^{27}$ Kerusakan hutan mangrove tersebut terjadi karena aktivitas manusia. Untuk itu diperlukan penegakan hukum yang kuat agar kerusakan hutan mangrove tidak lagi terjadi.

Kegiatan penegakan hukum dalam kerjasama REDD+ mencakup penanganan kebakaran hutan dan lahan yang dilakukan melalui penguatan regulasi, penguatan jaringan ahli hukum dan pengacara, penguatan jejaring dengan institusi teknis lainnya. Penguatan kapasitas penyidik pegawai negeri sipil lingkungan dan kehutanan (PPNS LHK). Selama ini pendekatan yang dilakukan dalam penanganan kasus kebakaran hutan dan lahan adalah pendekatan multi instrument, yaitu menerapkan secara bersamaan sanksi administrasi, penegakan hukum pidana dan penegakan hukum perdata bagi orang dan atau pengusaha (korporasi) pembakaran hutan dan lahan. Penanganan kasus kebakaran hutan dan lahan terus dikembangkan guna memberikan efek jera bagi pelakunya. Model yang dipilih adalah penerapan multi rezim hukum (multidoors), yaitu satu kasus ditangani oleh banyak institusi sesuai tugas dan fungsinya. ${ }^{28}$

Potensi hambatan REDD+ akan muncul terutama dari aspek-aspek kelembagaan, peraturan/ perundangan dari pada aspek teknis. ${ }^{29}$ Dari segi peraturan perundangundangan belum ada yang mengatur khusus terkait pengelolaan dan perlindungan terhadap hutan mangrove. Mengenai sistem multidoors yang diterapkan pemerintah bagi pelaku perusak lingkungan merupakan suatu hal yang bagus yang diterapkan pemerintah. Tidak tertutup kemungkinan berlaku bagi para lembaga penegak hukum, pejabat negara, pengusaha/korporasi yang melakukan penyimpangan terkait pemberian izin. Mengingat para penegak hukum dan pejabat negara sangat rentan terhadap praktek suap dan korupsi. Proyek REDD+ oleh sebagian pakar lingkungan dianggap sebagai "ladang baru korupsi" di Indonesia. Hal ini dikarenakan banyaknya uang yang beredar akibat program $R E D D+.30$

Program REDD+ yang diterapkan pada Kyoto Protocol yang dilakukan melalui mekanisme pasar menemui kegagalan dikarenakan tingginya praktek korupsi di bidang lingkungan hidup di Indonesia. ${ }^{31}$ Bila Paris Agreement masih tetap mengikuti pola tersebut maka besar kemungkinan program REDD+ dibawah Paris Agreement juga akan mengalami kegagalan.

${ }^{27}$ Statistik Sumber Daya Laut dan Pesisir.supra. Lihat catatan kaki No.25, h. 23

28 Yunus, M. (2016). Prosiding "REDD+ Indonesia Day" Seminar Nasional dan Pameran Bersama, "Moving REDD+ Indonesia Forward : Resolving Challenges-Seri II : Program REDD+ Fase Transisi Kerjasama RI-Norway: Komponen Penegakan Hukum. Jakarta: Direktorat Jenderal Pengendalian Perubahan Iklim Kementerian Lingkungan Hidup dan Kehutanan, h. 29

${ }^{29}$ Murdiyarso, D. (2016). Prosiding "REDD+ Indonesia Day" Seminar Nasional dan Pameran Bersama, "Moving REDD+ Indonesia Forward : Resolving Challenges-Seri II : Indonesia REDD+ After Paris: Quo Vadis?. Jakarta: Direktorat Jenderal Pengendalian Perubahan Iklim Kementerian Lingkungan Hidup dan Kehutanan, h. 35

${ }^{30}$ Husin, S. (2015). Pengurangan Emisi Karbon dioksida di Sektor Kehutanan Melalui Program REDD+ dan Optimalisasi Hukum Pidana Sebagai Wujud Kepatuhan Indonesia Terhadap Konvensi Perubahan Iklim. Universitas Andalas

${ }^{31}$ Husin, S., \& Tegnan, H. (2017). Corruption Eradication within the Protection of the Environment in Indonesia. Asian Journal of Water, Environment and Pollution, 14(4), p. 100 
Peraturan perundang-undangan merupakan salah satu aspek penting yang akan dijadikan pedoman bagi penyelenggara pemerintahan dan masyarakat yang menciptakan kepastian hukum yang menjadi faktor keberhasilan program REDD+ berbasis blue carbon. Undang-Undang Nomor 32 Tahun 2009 tentang Perlindungan dan Pengelolaan Lingkungan Hidup dan Undang-Undang Nomor 41 Tahun 1999 tentang Kehutanan masih menjadi acuan terkait hutan mangrove. Selain itu termasuk juga Undang-Undang Nomor 32 Tahun 2014 tentang Kelautan dan Undang-Undang Nomor 27 Tahun 2007 tentang Pengelolaan Wilayah Pesisir dan Pulau-Pulau Kecil. Pada tahun 2012 Presiden mengeluarkan Peraturan Presiden Nomor 73 Tahun 2012 tentang strategi nasional pengelolaan ekosistem mangrove. Perpres inilah yang menjadi peraturan yang khusus mengatur terkait pengelolaan ekosistem mangrove termasuk juga didalamnya perlindungan terhadap ekosistem mangrove. Perpres ini dikeluarkan masih pada rezim berlakunya Kyoto Protocol 1 dan sampai sekarang masih dijadikan acuan dalam pengelolaan hutan mangrove.

Peraturan Presiden Nomor 73 Tahun 2012 menyiratkan strategi nasional yang akan dilakukan pemerintah pusat dan pemerintah daerah untuk melakukan pengelolaan terhadap ekosistem mangrove, hal ini ditindaklanjuti juga dengan dikeluarkannya sejumlah peraturan daerah sebagai bentuk otonomi daerah oleh masing-masing kepala daerah. Namun dilihat kenyataannya amanat dari Peraturan Presiden Nomor 73 Tahun 2012 tidak berjalan sebagaimana mestinya. Adapun sejumlah peraturanperaturan yang didapat dari sejumlah daerah terkait pengelolaan mangrove diantaranya Peraturan Daerah Provinsi Sulawesi Selatan Kab Maros Nomor 03 Tahun 2015 tentang Pelestarian Mangrove, Peraturan Daerah Jawa Barat Nomor 6 tahun 2011 tentang Pengurusan Hutan Mangrove dan Hutan Pantai, Peraturan Daerah Kabupaten Raja Ampat Nomor 8 tahun 2012 tentang Perlindungan Hutan Mangrove dan Hutan Pantai, Peraturan Daerah Pemrov Gorontalo Nomor 7 tahun 2016 tentang Pengelolaan Ekosistem Mangrove, Peraturan Gubernur Jawa Barat Nomor 28 tahun 2013 tentang Petunjuk Pelaksanaan Peraturan Daerah Provinsi Jawa Barat Nomor 6 tahun 2011 tentang Pengurusan Hutan Mangrove dan Hutan Pantai. Peraturan Daerah Kabupaten Mimika Nomor 12 tahun 2014 tentang Perlindungan dan Pengelolaan Ekosistem Mangrove.

Melihat kondisi tersebut sangat sedikit sekali pemerintah daerah yang belum membuat peraturan terkait perlindungan hutan mangrove di daerah pemerintahannya. Melalui asas otonomi daerah pemerintah daerah wajib memelihara dan mengelola mangrove. Dalam hal ini pemerintah daerah memegang peranan yang sangat penting dalam mengelola ekosistem mangrove. Meskipun dalam Undang-Undang Nomor 32 Tahun 2009, bagi penyelenggara pemerintahan yang lalai mengelola kawasan mangrove bisa dikenakan sanksi. Namun, tetap saja peraturan belum efektif dilaksanakan.

Dilihat dari peraturan-peraturan yang dikeluarkan pemerintah daerah terkait hutan mangrove masih merupakan produk dari rezim Kyoto Protocol, peraturan yang dihasilkan dibawah rezim Paris Agreement terkait perlindungan mangrove masih belum nyata terlihat saat ini. Peraturan dibuat guna melindungi ekosistem mangrove yang berada di kawasan pesisir pantai yang sangat rentan terjadinya perusakan lingkungan. Dalam upaya untuk menjaga kelestarian hutan mangrove termasuk konservasi dan rehabilitasi dibutuhkan peran tidak saja dari pemerintah pusat, daerah, 
namun peran yang juga sangat penting adalah peran masyarakat yang ada di sekitar daerah pesisir pantai.

Kunci untuk konservasi hutan mangrove tergantung dari jenis aktivitas manusia di daerah aliran sungai mangrove. dengan demikian akan muncul sebuah komitmen lokal terhadap ekosistem di sekitarnya. ${ }^{32}$ Selain itu, penetapan kawasan tenurial masyarakat adat perlu diperjelas oleh pemerintah, sehingga tidak ada lagi masyarakat dirugikan dalam penetapan kawasan hutan. Tidak sedikit juga terjadi konflik antara pemerintah dan masyarakat.

\section{Kesimpulan}

Diratifikasinya Paris Agreement to the UNFCCC oleh Indonesia menjadikan Paris Agreement sebagai bagian dari hukum nasional di Indonesia, Indonesia terikat secara hukum pada Paris Agreement untuk melaksanakan hak-hak dan kewajiban-kewajiban yang terdapat dalam Paris Agreement. Untuk melaksanakan kewajiban dalam Paris Agreement berimplikasi pada dibentuknya sejumlah peraturan pelaksana di Indonesia. Persoalan hukum dalam implementasi Paris Agreement adalah penegakan hukum, kepastian hukum. Penegakan hukum yang masih lemah dalam menindak pelakupelaku kerusakan hutan, kepastian hukum berupa belum tersedianya aturan baru yang khusus mengatur tentang perlindungan dan pengelolaan terhadap hutan mangrove.

\section{Daftar Pustaka}

Buku

Djamal Irwan, Z. (2014). Prinsip-Prinsip Ekologi Ekosistem, Lingkungan dan Pelestariannya, Jakarta: PT.Bumi Aksara.

Edy, S. (1988). Praktek Ratifikasi Perjanjian Internasional di Indonesia. Bandung: Remadja Karya.

Husin, S. (2016). Hukum Internasional Dan Indonesia Tentang Perubahan Iklim. Jakarta: PT. Rajagrafindo Persada.

Baderan, D.W.K. (2017). Serapan Hutan Mangrove Gorontalo. Yogyakarta: Deepublish.

Kementerian Lingkungan Hidup dan Kehutanan.(2017). Summary Nationally Determined Contribution (NDC) dan Progres. Jakarta.

Sands, P. (2003). Principles of International Environmental Law. Cambridge: Cambridge University Press.

Soekanto, S. (2008). Pengantar Penelitian Hukum. Jakarta: Universitas Indonesia.

Soekanto, S., \& Mamudji, S. (2006). Penelitian Hukum Normatif, Suatu Tinjauan Singkat.Jakarta: Rajawali Pers.

Statistik Sumber Daya Laut dan Pesisir. (2016). Jakarta: Badan Pusat Statistik.

Statistik Sumber Daya Laut dan Pesisir. (2017). Jakarta: Badan Pusat Statistik.

\section{Jurnal dan Prosiding}

Husin, S., \& Tegnan, H. (2017). Corruption Eradication within the Protection of the Environment in Indonesia. Asian Journal of Water, Environment and Pollution, 14(4), 99-108. https://doi.org/10.3233/AJW-170040

\footnotetext{
32 Wardhani, M.K. (2014). Analisis Kesesuaian Lahan Konservasi Hutan Mangrove di Pesisir Selatan Kabupaten Bangkalan. Journal Trunojoyo, 7(2), h. 72
} 
Murdiyarso, D. (2016). Indonesia REDD+ After Paris: Quo Vadis?. Moving REDD+ Indonesia Forward: Resolving Challenges-Seri II

Sari, A.P.(2016). Stranas dan Srap/Strada REDD+ dan Implikasi Paris Agreement: Quo Vadis REDD+ After Paris ?. Moving REDD+ Indonesia Forward : Resolving ChallengesSeri II

Yunus, M. (2016). Program REDD+ Fase Transisi Kerjasama RI-Norway: Komponen Penegakan Hukum. Moving REDD+ Indonesia Forward: Resolving Challenges-Seri II

Wardhani, M. K. (2014). Analisis Kesesuaian Lahan Konservasi Hutan Mangrove di Pesisir Selatan Kabupaten Bangkalan. Jurnal Kelautan: Indonesian Journal of $\begin{array}{llll}\text { Marine Science } & \text { 69-74. }\end{array}$ http://dx.doi.org/10.21107/jk.v7i2.799

Widjaksono, A.G., MAS. (2016). Instrumen Pendanaan. Moving REDD+ Indonesia Forward : Resolving Challenges-Seri II

\section{Disertasi}

Husin, S. (2015). Pengurangan Emisi Karbon dioksida di Sektor Kehutanan Melalui Program REDD+ dan Optimalisasi Hukum Pidana Sebagai Wujud Kepatuhan Indonesia Terhadap Konvensi Perubahan Iklim. Universitas Andalas.

\section{Website}

United Nation Climate Change. Parties \& Observers.. Retrieved from https://unfccc.int/parties-observers

United Nation Climate Change. Indonesia INDC. Retrieved from http://unfccc.int/ndcregistry/publisheddocuments/indonesiafirst/firstNDCi ndonesia_submittedtoUNFCCC

\section{Peraturan Perundang-Undangan}

Republik Indonesia. 1994. Undang-Undang Nomor 6 tahun 1994 tentang Pengesahan United Nation Framework Convention On Climate Change/UNFCCC. Lembaran Negara RI Tahun 1994, No.42. Sekretariat Negara. Jakarta

Republik Indonesia. 2004. Undang-Undang Nomor 17 tahun 2004 tentang Pengesahan Kyoto Protocol To The UNFCCC. Lembaran Negara RI Tahun 2004, No.72. Sekretariat Negara. Jakarta

Republik Indonesia. 2016. Undang-Undang Nomor 16 tahun 2016 tentang Pengesahan Paris Agreement To The UNFCCC. Lembaran Negara RI Tahun 2016, No.204. Menkumham. Jakarta

Republik Indonesia. 1999. Undang-Undang Nomor 41 tahun 1999 tentang kehutanan. Lembaran Negara RI Tahun 1999, No.167. Sekretariat Negara. Jakarta

Republik Indonesia. 2009. Undang-Undang Nomor 32 tahun 2009 tentang Perlindungan Dan Pengelolaan Lingkungan Hidup. Lembaran Negara RI Tahun 2009, No.140. Sekretariat Negara. Jakarta 